\title{
CAMPANHAS E LEGISLAÇÃO ELEITORAL:ANÁLISE DA “MINIRREFORMA" NO CONTEXTO DAS ELEIÇÕES MUNICIPAIS BRASILEIRAS DE 2016
}

\author{
Mércia Alves ${ }^{3}$ \\ Bárbara Lima ${ }^{4}$
}

\begin{abstract}
RESUMO
As eleições 2016 foram marcadas pelas mais significativas alterações na legislação eleitoral das duas últimas décadas. Essas mudanças foram promovidas principalmente pela minirreforma eleitoral de 2015, que alterou o perfil de financiamento e o tempo das campanhas eleitorais. O objetivo deste artigo é analisar a dinâmica financeira das campanhas em 2012 e 2016, a partir da minirreforma e do caso das eleições municipais. Foram selecionadas as campanhas eleitorais vitoriosas de dez capitais brasileiras, sendo elas: São Paulo, Belo Horizonte, Rio de Janeiro, Salvador, Fortaleza, Curitiba, Cuiabá, Manaus, Campo Grande e Recife. Foram analisados, especificamente, 1) dados sobre os colégios eleitorais nos dez municípios, para as eleições de 2012 e 2016, e 2) as prestações de contas oficiais elaboradas pelos partidos e entregues ao TSE, também referentes às campanhas de 2012 e 2016.
\end{abstract}

Palavras-chave: Eleições municipais. Eleições 2016. Campanha eleitoral. Legislação. Minirreforma eleitoral.

\begin{abstract}
The elections of 2016 were marked by the most significant changes in the electoral legislation in the last two decades. These changes were promoted mainly by the mini electoral reform of 2015 , that changed the profile of electoral campaign time and funding. The aim of this article is to analyze the financial dynamics of the 2015 electoral reform on the municipal elections case. The ten winning electoral campaigns among Brazilian capitals were selected. They are: São Paulo, Belo Horizonte, Rio de Janeiro, Salvador, Fortaleza, Curitiba, Cuiabá, Manaus, Campo Grande and Recife. The collected data were 1) the electoral colleges in the selected cities in the elections of 2012 and 2016 and 2) the official accounts made by the parties and delivered to the TSE, in regarding of the campaigns of 2012 and 2016.
\end{abstract}

Keywords: Municipal elections. Elections of 2016. Election campaign. Legislation. Mini electoral reform.

\section{RESUMEN}

Las elecciones de 2016 fueron marcadas por los cambios más significativos en la legislación electoral de las dos últimas décadas. Estos cambios fueron promovidos principalmente por la "Minirreforma" Electoral de 2015, que alteró el perfil de la financiación, y el tiempo de campaña. El objetivo es analizar la dinámica financiera de las campañas en 2012 y 2016, a partir de la "Minirreforma" a partir del caso de las elecciones municipales. Se seleccionaron las campañas electorales victoriosas de 10 capitales brasileñas. Son: Sao Paulo, Belo Horizonte, Río de Janeiro, Salvador, Fortaleza, Curitiba, Cuiabá, Manaus, Campo, Grande y Recife. Específicamente: 1) datos sobre los colegios electorales en los 10 municipios para las elecciones de 2012 y 2016; 2) las prestaciones de cuentas oficiales elaboradas por los partidos y entregadas al TSE referentes a las campañas de 2012 y 2016.

Palabras Clave: Elecciones Municipales; Elecciones 2016; Campaña electoral; legislación; "Minirreforma" Electoral.

\footnotetext{
${ }^{1}$ Enviado: 20/09/2017. Aceito: 13/11/2017.

2 DOI: http://dx.doi.org/10.5380/recp.v9i1.55339

${ }^{3}$ Doutoranda em Ciência Política (PPGPOL/UFSCar); membro do grupo de pesquisa Comunicação Política, Partidos e Eleições - UFSCar e do Núcleo de Estudos em Arte, Mídia e Política - NEAMP, PUC-SP. Bolsista da Fundação de Amparo à Pesquisa do Estado de São Paulo (FAPESP). E-mail: mercia_f.alves@ @otmail.com.

${ }^{4}$ Doutoranda em Ciência Política (PPGPOL/UFSCar); membro do grupo de pesquisa Comunicação Política, Partidos e Eleições - UFSCar. E-mail: barbaracslima@gmail.com.
} 
ALVES, M; LIMA, B. Campanhas e legislação eleitoral: análise da "minirreforma" no contexto das eleições municipais brasileiras de 2016

\section{INTRODUÇÃO}

As eleições municipais de 2016 foram marcadas por darem início a uma nova configuração das normas eleitorais no Brasil. Apesar de a legislação sofrer alterações a cada pleito, as características fundamentais das campanhas vinham se mantendo desde a Lei $\mathrm{n}^{\circ}$ 9.504/1997, tais como as regras para coligações partidárias, o acesso gratuito dos partidos políticos aos meios de comunicação e a divisão de tempo baseada no tamanho das bancadas dos partidos e o financiamento misto de campanhas (que combina doações individuais, de pessoas jurídicas e dos diretórios dos partidos). Porém, alterações consideráveis puderam ser observadas com a minirreforma de 2015 , que promoveu mudanças na forma como os partidos e candidatos organizam as suas campanhas.

A lei objetiva diversas mudanças, estando, entre as principais e mais substantivas delas, aquelas no perfil do financiamento - a partir da proibição da doação de recursos por pessoas jurídicas - e na diminuição do tempo de campanha - ou seja, dos dias de Horário Gratuito de Propaganda Eleitoral (HGPE). Essas alterações visam garantir aos partidos e candidatos uma maior equidade em relação a disponibilidades de recursos, tendo como principal justificativa a diminuição do custo das campanhas.

Sendo assim, as eleições municipais de 2016 são um importante objeto de análise, principalmente para estudos que relacionam as mudanças institucionais com o comportamento dos atores políticos. O objetivo, aqui, é analisar a dinâmica financeira da minirreforma de 2015, a partir do caso das eleições municipais em dez capitais brasileiras, privilegiando-se as mudanças na lei eleitoral a partir da identificação dos problemas que estas visaram sanar.

A análise será feita em duas etapas. No plano teórico, será abordada a literatura sobre campanhas e o seu processo de modernização, seus fatores encarecedores e a legislação eleitoral brasileira, desde suas principais alterações até a Lei $n^{\circ} 13.165 / 2015$, seguida da discussão sobre o financiamento das campanhas no Brasil. Em seguida, será feita uma análise mais prática a respeito das campanhas políticas no Brasil, a partir das prestações de contas oficiais elaboradas pelos partidos e submetidas ao Tribunal Superior Eleitoral (TSE). Tais dados serão analisados de forma comparada, visando-se as mudanças promovidas pela minirreforma. Trataremos das dez capitais com maiores colégios eleitorais (TSE, 2016): São Paulo, Belo Horizonte, Rio de Janeiro, Salvador, Fortaleza, Curitiba, Cuiabá, Manaus, Campo, Grande e Recife. 


\section{MODERNIZAÇÃO DAS CAMPANHAS ELEITORAIS}

As campanhas eleitorais no Brasil, em sua atual configuração, são consideradas pela literatura como em um estágio avançado de modernização. Esse fenômeno teve início em meados da década de 1950 nos Estados Unidos, no auge do advento da televisão, que surge como elemento central das campanhas, sendo a principal via de comunicação entre candidato e eleitor e palco para o acirramento da competição eleitoral (NORRIS, 2000). A implantação desse modelo prevê mudanças em diferentes bases da organização e gestão das campanhas, nas quais são utilizados profissionais e consultores externos ao partido, os quais utilizam novas ferramentas e técnicas de comunicação com o objetivo de ambientar tais campanhas à lógica mercadológica e comunicacional (FARRELL, 2006; LISI, 2011).

Outros processos paralelos podem ser observados nas campanhas, relacionados à adaptação da sua comunicação à lógica da TV: a personalização e a profissionalização. As principais consequências da utilização desses processos são a centralidade da imagem do candidato nos períodos eleitorais em detrimento do protagonismo dos partidos políticos (MANIN, 1995, 2013) e o encarecimento das campanhas, devido à adoção de técnicas de marketing e à contratação de pessoal especializado, além do uso ostensivo de pesquisas de sondagem de opinião (FARRELL, 2006) e, mais recentemente, das novas tecnologias de informação e comunicação (AZEVEDO, 2006; NORRIS, 2000; MAZZOLENI, 2010).

Nesse cenário, os meios de comunicação de massa e, principalmente, a TV são os espaços por meio dos quais a imagem e o discurso dos candidatos são situados e legitimados no ambiente de campanha (MAZZOLENI, 2010), além de onde as estratégias eleitorais são estabelecidas. No Brasil, o HGPE é o modelo de propaganda televisivo institucionalizado pela Lei $n^{\circ} 9.504 / 1997$, que dita as conformidades de uso da propaganda e o tempo de exposição de cada coligação. O espaço gratuito de propaganda eleitoral no rádio e na televisão é garantido pela legislação eleitoral brasileira desde 1960, apesar da liberdade de expressão dos candidatos ter sido amplamente reduzida no período do regime militar.

De acordo com Albuquerque (2005), com a redemocratização em 1985, a legislação eleitoral foi modificada e o Tribunal Superior Eleitoral tornou-se o responsável pela execução das eleições no Brasil. Desde então a legislação eleitoral sofreu diversas inflexões ao longo dos pleitos, mantendo-se garantido, entretanto, o acesso gratuito ao rádio e à televisão, cujo tempo é concedido de acordo com a bancada parlamentar e cujas campanhas são veiculadas numa ordem pré-determinada (ALBUQUERQUE, 2005). Ao longo de duas décadas de 
ALVES, M; LIMA, B. Campanhas e legislação eleitoral: análise da "minirreforma" no contexto das eleições municipais brasileiras de 2016

eleições diretas a legislação eleitoral foi reformulada e aprimorada, como veremos na próxima seção.

\subsection{LEGISLAÇÃO ELEITORAL NO BRASIL}

A primeira mudança significativa na legislação eleitoral brasileira ocorreu em 1994, quando foi proibida a presença de terceiros e o uso de recursos comunicativos e efeitos visuais nas campanhas. Porém, essa regra se manteve apenas neste pleito. Nas eleições seguintes, em 1996, a mudança mais relevante se deu com a incorporação dos spots eleitorais, inserções de 30 ou 60 segundos exibidas durante a programação normal das emissoras abertas. Diferente do HGPE, esses comerciais aparecem esporadicamente e surpreendem o telespectador, uma vez que não têm um horário fixo de exibição. Os spots ajudaram a desenvolver outras técnicas de campanha, como a propaganda negativa e os ataques aos outros candidatos (BORBA, 2012).

A lei eleitoral estabelecida em 1997 (BRASIL, 1997) é a que rege a maioria das regras em vigência até hoje. Seu texto, porém, passou por mudanças nos anos de 2006, 2009, 2013 e 2015, com a minirreforma. Interessam-nos, aqui, as mudanças que afetam diretamente a comunicação e a organização financeira das campanhas, sendo que a primeira delas ocorreu em 2006 com a Lei $n^{\circ}$ 11.300, quando foram vetados diversos recursos de divulgação dos partidos e candidatos, conforme apresentado nos parágrafos $\S 6^{\circ}$, $\S 7^{\circ}$ e $\S 8^{\circ}$ do art. 36, em que se vedam a confecção, utilização e distribuição, por comitês e/ou candidatos, de brindes (camisetas, chaveiros, bonés, canetas etc.), cestas básicas ou quaisquer outros bens materiais que possam atribuir vantagens ao eleitor.

Proibiu-se no mesmo ano a contratação e o pagamento de cachês a artistas, bem como a realização de showmícios ${ }^{5}$ e eventos similares que tivessem por objetivo a promoção do candidato, sendo permitidos apenas os tradicionais comícios a céu aberto e as reuniões sem caráter de entretenimento. Foi proibida, também, a concessão pública e de propaganda em outdoors, além de, finalmente, em conformidade com o art. 43, parágrafo único, ter sido delimitado o direito de divulgação pago na imprensa escrita.

No ano de 2009, com a Lei $n^{\circ} 12.034$, houve mudanças principalmente na disposição das propagandas externas, quando regulamentou-se o uso de cavaletes, bonecos, cartazes e mesas de destruição de material, desde que os mesmos não atrapalhassem a mobilidade das

\footnotetext{
5 O termo "showmício" se refere à contratação de artistas, remunerados ou não, com o objetivo de animar comícios e/ou reuniões eleitorais.
} 
vias públicas e fossem ali colocados em horários preestabelecidos. Proibiu-se, também, a colocação de material publicitário em parques, jardins e árvores, bem como em muros, tapumes e cercas.

As mudanças observadas na Lei ${ }^{\circ} 12.891 / 2013$ foram um prelúdio da minirreforma de 2015. A discussão sobre a reforma eleitoral foi fomentada pelas manifestações de julho de 2013, mas, devido ao fato de pouco discutir-se a sua regulamentação, boa parte da reforma foi realizada somente em 2015'. As principais mudanças implementadas em 2013 estão relacionadas à realização de eventos e comícios partidários e à regulamentação do uso de carros de som e trios elétricos para sua divulgação.

Como foi citado acima, as mudanças constantes na legislação objetivam adequar as regras relacionadas às campanhas eleitorais ao contexto sociopolítico de cada pleito. Com novas tecnologias de informação e comunicação, as campanhas ganharam novos espaços de diálogo entre candidato e eleitor. Neste sentido, nas últimas eleições foram criadas regras que visaram regulamentar a propaganda on-line. A primeira foi a resolução $\mathrm{n}^{\circ} 20.684$, de 2000 , que especificava o uso do domínio on-line, por meio do qual a propaganda seria realizada nas eleições presidenciais seguintes, seguida pela resolução $\mathrm{n}^{\circ} 20.988$, de 2002, que submetia a propaganda na internet às mesmas limitações da propaganda veiculada no rádio e na televisão.

Em 2009, a Lei $n^{\circ} 12.034^{7}$ previu a possibilidade de se realizarem doações para as campanhas operadas via internet. Quanto ao conteúdo, a mesma lei impôs limites às matérias de cunho jornalístico e às mensagens consideradas ofensivas aos demais candidatos, além de instaurar o direito de resposta nas plataformas on-line. Ainda, delimitou os espaços onde a propaganda era permitida, estando entre eles os endereços eletrônicos dos candidatos e dos partidos, os blogs e as redes sociais. Essa lei foi incluída no conjunto de regras da Lei $\mathrm{n}^{\mathbf{o}}$ 9504/97 e é readequada a cada pleito de acordo com a evolução e o desenvolvimento das ferramentas digitais de comunicação.

Desde 2009 a legislação eleitoral prevê a utilização dos ambientes on-line para lançar oficialmente candidaturas. Os esforços mais recentes da lei referentes às campanhas on-line, feitos em 2013 e $2015^{8}$, se concentram em delimitar os tipos de propaganda permitidos,

\footnotetext{
${ }^{6}$ De acordo com o art. 16 da Constituição Federal, "a lei que alterar o processo eleitoral entrará em vigor na data de sua publicação, não se aplicando à eleição que ocorra até um ano da data de sua vigência". Em sessão administrativa em junho de 2014, o plenário do TSE decidiu que este artigo se aplicava às reformas discutidas em 2013 e que, portanto, tais reformas não entrariam em vigor para as eleições de 2014 (TSE, 2014).

${ }^{7}$ A primeira menção à internet na legislação foi encontrada no art. $28, \S 4^{\circ}$, em que exige-se a disponibilização da prestação de contas on-line.

${ }^{8}$ Lei no $^{\circ} 12.891$ e Lei n ${ }^{\circ} 13.165$.
} 
ALVES, M; LIMA, B. Campanhas e legislação eleitoral: análise da "minirreforma" no contexto das eleições municipais brasileiras de 2016

proibir a veiculação de propagandas pagas em sites de pessoas físicas e/ou outdoors eletrônicos e estipular o que configura "propaganda antecipada". Além disso, discute-se sobre ofender a honra e/ou denegrir a imagem de outro candidato ou partido, tanto em sites quanto em redes sociais, assim como os devidos direito de resposta e punição nesses casos.

Por se tratarem de meios de comunicação mais dinâmicos se comparados à $\mathrm{TV}$, ao rádio e aos materiais impressos, existe uma maior dificuldade no controle do conteúdo on-line nos períodos eleitorais, principalmente na classificação do que pode ser considerado propaganda fora do período oficial de campanha, o que é vedado pela justiça eleitoral. Ademais, o TSE vem, nos últimos anos, ampliando os seus mecanismos de controle sobre as campanhas, principalmente quanto à prestação de contas, aos planos de governo e à disposição on-line, para acesso público, das informações pessoais dos candidatos, tais como informações sobre suas carreiras políticas e profissionais e seu patrimônio.

\section{FINANCIAMENTO E LEGISLAÇÃO ELEITORAL}

Os gastos com atividades de campanha no Brasil seguiram sempre crescendo. Um dos principais fatores a contribuir para tanto é o encarecimento dos serviços técnicos prestados por terceiros (MARENCO, 2008), muitos deles relacionados aos aspectos organizacionais do processo de modernização e profissionalização das campanhas. Porém, antes dos gastos, o debate sobre o perfil do financiamento das campanhas no Brasil é uma questão que, nos últimos anos, entrou na agenda pública. $\mathrm{O}$ debate entre público e privado reúne alguns argumentos centrais, sendo o primeiro deles aquele que relaciona o investimento privado às práticas de corrupção (SPECK, 2012).

Outro argumento relevante contra o financiamento privado é o de Ribeiro (2006), que enfatiza a dependência de partidos e candidatos do setor privado, além do aumento da desigualdade entre candidatos que recebem doações dessa categoria e aqueles que não despertam o interesse das empresas. Em contrapartida, a proibição desse tipo de investimento pode aumentar a dependência do investimento público em campanhas eleitorais, causando uma maior dependência dos recursos do Estado, que hoje não investe diretamente em campanhas eleitorais (RIBEIRO, 2006) ${ }^{9}$.

\footnotetext{
${ }^{9}$ O Estado brasileiro não investe diretamente nas campanhas eleitorais, mas concede aos partidos políticos e coligações um espaço na TV e no rádio, por meio dos spots de propaganda partidária, do HGPE e dos spots eleitorais.
} 
Foi a partir da Lei $\mathrm{n}^{\circ} 8.713 / 1993$ que partidos e candidatos passaram a poder receber doações de pessoas jurídicas. A mesma lei estabeleceu a obrigatoriedade da prestação de contas eleitorais de partidos e comitês financeiros junto à justiça eleitoral, que as divulga ao público. Diferentemente da maioria dos países (SAMUELS, 2006), a prestação de contas é realizada, no Brasil, por meio de regras e mecanismos de controle de origem específicos (CERVI, 2013), dispostos na Lei $n^{\circ} 9.504 / 97$ (art. 23, $\S 1^{\circ}$, art. I e II, $\S 7^{\circ}$ e art. $81, \S 1^{\circ}$ ), segundo a qual pessoas físicas podem doar até $10 \%$ dos seus rendimentos brutos, enquanto pessoas jurídicas podem doar até $2 \%$, tendo-se como referência para tais percentuais os valores declarados à Receita Federal no ano anterior ao eleitoral.

Segundo dados do TSE (2012), nas eleições gerais de 2010, 74,4\% dos recursos investidos em campanhas eleitorais no Brasil tiveram origem de pessoas jurídicas, ao passo que o volume de recursos arrecadados a partir de doações de pessoas físicas foi de $14,5 \%$. A terceira maior fonte de recursos teve origem no patrimônio próprio dos candidatos, sendo ela de $10,2 \%$, sendo que o fundo partidário foi responsável por apenas $0,2 \%$ do total de recursos despendidos para as campanhas. Ainda, parte considerável das doações de pessoas jurídicas provinha de poucas empresas de grande porte, uma vez que a legislação brasileira estabelece um percentual limite relativamente baixo.

Segundo Mancuso e Ferraz (2012), sobre as eleições de 2010, metade das doações para as campanhas foi realizada por apenas 70 grupos empresariais, somando um total de dezenove mil reais. Ainda, segundo os mesmos autores, existe uma concentração de seguimentos entre os principais doadores, sendo eles construtoras, grupos financeiros, siderúrgicas, indústria de alimentos e bebidas e empresas de comunicação. Esses grupos destinam recursos para diversos candidatos, muitas vezes independentemente de qualquer posicionamento político, ideológico ou plano de governo.

Em resumo, as doações de pessoas jurídicas no Brasil parecem seguir principalmente o critério referente às chances eleitorais dos candidatos, contribuindo para um ciclo que se retroalimenta. Além disso, há um padrão nas contribuições no Brasil segundo o qual as empresas investem, mais do que as pessoas físicas (SAMUELS, 2006), um maior volume de recursos, e em candidatos e partidos com mais chances eleitorais. Isso pode gerar um desequilíbrio na disputa entre candidaturas com maior e menor disponibilidade de recursos.

Em suma, o volume de dinheiro investido nas campanhas é uma das variáveis para a compreensão dos seus resultados eleitorais (SAMUELS, 2001, 2002; MARCELINO, 2010; PEIXOTO, 2010; CERVI, 2010; MANCUSO; SPECK, 2012), uma vez que candidatos com maior disponibilidade de dinheiro podem investir mais e melhor em atividades fundamentais 
ALVES, M; LIMA, B. Campanhas e legislação eleitoral: análise da "minirreforma" no contexto das eleições municipais brasileiras de 2016

(tais como a realização de pesquisas de opinião) e naquelas relacionadas à comunicação (como a produção de material publicitário impresso e para os meios de comunicação, desde o rádio e a TV até a internet).

\section{ANÁLISE DA MINIRREFORMA NO CONTEXTO DAS ELEIÇÕES MUNICIPAIS DE 2012 E 2016}

Foram selecionadas empiricamente as campanhas eleitorais vitoriosas de dez capitais brasileiras. São elas: São Paulo, Belo Horizonte, Rio de Janeiro, Salvador, Fortaleza, Curitiba, Cuiabá, Manaus, Campo Grande e Recife. O objetivo, aqui, é analisar a dinâmica financeira das campanhas após a minirreforma de 2015 a partir do caso das eleições municipais. Para tanto, serão utilizados: 1) dados sobre os colégios eleitorais nos dez municípios selecionados, relativos às eleições de 2012 e 2016; e 2) as prestações de contas oficiais elaboradas pelos partidos e entregues ao TSE referentes às campanhas de 2012 e 2016. A partir disso, serão realizados quatro testes empíricos.

No primeiro teste, será relacionada a disponibilidade de recursos com que cada uma das campanhas vencedoras contou ao número de turnos das eleições de 2012 e 2016, com o objetivo de se avaliar o quanto as campanhas de 2016 custaram em relação à anterior, considerando-se as alterações específicas previstas pela minirreforma - a proibição das doações por pessoas jurídicas e a diminuição dos dias de campanha. Em segundo lugar, portanto, serão apresentados os dados a respeito das doações de pessoas jurídicas a essas campanhas para as eleições de 2012.

No terceiro teste será avaliado o total de gastos das campanhas dos candidatos vencedores nas dez capitais em 2012 e 2016, em paralelo com o teto estipulado pela minirreforma. O quarto teste, por fim, tem como propósito avaliar os fatores encarecedores das campanhas eleitorais, buscando-se responder a algumas perguntas: a TV reúne o maior volume de gastos nas campanhas selecionadas para análise? Quanto custa o pessoal contratado para as campanhas? A finalidade, aqui, é avaliar se a restrição — de tempo, no primeiro caso, e de número, no segundo - determinada pela lei da minirreforma eleitoral de 2015 é coerente com o objetivo de tornar as campanhas menos caras.

Assim, a primeira tabela apresenta dados sobre o colégio eleitoral nas dez capitais analisadas, sendo este um dos critérios utilizados para o estabelecimento do teto de gastos pela minirreforma e, também, para a contratação de terceiros para a realização de atividades 
específicas de campanha - duas das três mais importantes e significativas alterações em voga já na campanha de 2016.

TABELA 1 - COLÉGIO ELEITORAL DE 2012 E 2016

\begin{tabular}{c|c|c|c}
\hline \multirow{2}{*}{ Cidade } & \multirow{2}{*}{ Estado } & \multicolumn{2}{|c}{ Colégios eleitorais } \\
\cline { 3 - 4 } & & 2012 & 2016 \\
\hline São Paulo & São Paulo & 8.619 .170 & 8.886 .324 \\
\hline Belo Horizonte & Minas Gerais & 1.860 .172 & 1.927 .460 \\
\hline Rio de Janeiro & Rio de Janeiro & 4.719 .607 & 4.898 .045 \\
\hline Salvador & Bahia & 1.881 .544 & 1.948 .154 \\
\hline Fortaleza & Ceará & 1.612 .155 & 1.692 .712 \\
\hline Curitiba & Paraná & 1.172 .939 & 1.289 .215 \\
\hline Cuiabá & Mato Grosso & 397.626 & 415.100 \\
\hline Manaus & Amazonas & 1.178 .120 & 1.257 .129 \\
\hline Campo Grande & Mato Grosso do Sul & 561.630 & 595.147 \\
\hline Recife & Pernambuco & 1.169 .678 & 1.119 .271 \\
\hline
\end{tabular}

FONTE: O autor (2017).

A tabela acima apresenta as dez cidades escolhidas para análise, as quais, de acordo com o TSE, representam os maiores colégios eleitorais do país. Outras variáveis também contribuíram para a escolha de tais cidades como objetos de análise, como o fato de apresentarem disputas eleitorais acirradas e de, na maioria delas, as disputas serem constantemente levadas ao segundo turno. Ainda, como pode ser observado na Tabela 2, são, também, cidades que contam com filiais de emissoras e que, portanto, possuem um HGPE próprio. Pode-se observar através dos dados que todas as cidades apresentaram um aumento considerável de eleitores cadastrados de 2012 a $2016^{10}$.

TABELA 2 - CANDIDATOS VENCEDORES E NÚMERO DE TURNOS NAS ELEIÇÕES MUNICIPAIS DE 2012 E 2016 NAS DEZ CAPITAIS

\begin{tabular}{|c|c|c|c|c|c|c|}
\hline \multirow{3}{*}{ Cidade } & \multicolumn{6}{|c|}{ Candidatado vencedor } \\
\hline & \multicolumn{3}{|c|}{2012} & \multicolumn{3}{|c|}{2016} \\
\hline & Candidato & Partido & Turnos & Candidato & Partido & Turnos \\
\hline São Paulo & Fernando Haddad & PT & 2 & João Dória & PSDB & 1 \\
\hline Belo Horizonte & Marcio Lacerda & PSB & 1 & Alexandre Kalil & PHS & 2 \\
\hline Rio de Janeiro & Eduardo Paes & PMDB & 1 & Marcelo Crivella & PRB & 2 \\
\hline Salvador & ACM Neto & DEM & 2 & ACM Neto & DEM & 1 \\
\hline Fortaleza & Roberto Claudio & PSB & 2 & Roberto Cláudio & PDT & 2 \\
\hline Curitiba & Gustavo Fruet & PDT & 2 & Rafael Greca & PMN & 2 \\
\hline Cuiabá & Mauro Mendes & PSB & 2 & Emanuel Pinheiro & PMDB & 2 \\
\hline Manaus & Artur Neto & PSDB & 2 & Artur Neto & PSDB & 2 \\
\hline
\end{tabular}

\footnotetext{
${ }^{10}$ Com exceção de Recife, que apresentou uma baixa de cerca de 50 mil eleitores. Acredita-se que essa mudança foi ocasionada pelo recadastramento biométrico que ocorreu na cidade em 2014, como pode ser visto em um artigo do Tribunal Regional Federal da 5ª Região (2013).
} 
ALVES, M; LIMA, B. Campanhas e legislação eleitoral: análise da "minirreforma" no contexto das eleições municipais brasileiras de 2016

\begin{tabular}{c|c|c|c|c|c|c} 
Campo Grande & Alcides Bernal & PP & 2 & Marcos Trad & PSD & 2 \\
\hline Recife & Geraldo Julio & PSB & 1 & Geraldo Julio & PSB & 2 \\
\hline
\end{tabular}

FONTE: $\mathrm{O}$ autor (2017).

Das dez capitais analisadas, três estão localizadas na região Sudeste, três no Nordeste, uma no Sul, duas no Centro-Oeste e uma no Norte, sendo elas as capitais com maior colégio eleitoral nas eleições municipais de 2012 e 2016 e as cidades com maior teto de gastos de campanha para as eleições de 2016. Em outras palavras, são as maiores campanhas brasileiras em número de votantes e em gastos. Além disso, das dez cidades analisadas, sete levaram a decisão ao segundo turno em 2012, e oito em 2016 - outro elemento encarecedor dessas campanhas, considerando-se a relação entre tempo e custo que se estabelece nessas situações.

TABELA 3 - RECEITAS POR CIDADE EM MILHÕES DE REAIS, TOTAL DE RECEITAS DO CANDIDATO VENCEDOR NAS ELEIÇÕES MUNICIPAIS DE 2012 E 2016 E O PERCENTUAL DE DIMINUIÇÃO DE RECEITA NAS DEZ CAPITAIS

\begin{tabular}{c|c|c|c|c|c|c}
\hline \multirow{2}{*}{ Cidade } & \multicolumn{2}{|c|}{ Receita em 2012 } & \multicolumn{2}{c|}{ Receita em 2016 } & \multicolumn{2}{c}{ Percentual de diminuição } \\
\cline { 2 - 7 } & Total & Candidato & Total & Candidato & Total & Candidato \\
\hline São Paulo & 97.3 & 42 & 33.9 & 12.4 & 65,2 & 70 \\
\hline Belo Horizonte & 39.3 & 21.8 & 24.5 & 3.4 & 37,7 & 84,5 \\
\hline Rio de Janeiro & 30.4 & 21.2 & 25.8 & 8.7 & 15,2 & 59 \\
\hline Salvador & 42.2 & 21.9 & 10.1 & 8.3 & 76,1 & 62,2 \\
\hline Fortaleza & 34 & 18.5 & 17 & 9.8 & 50 & 47,1 \\
\hline Curitiba & 29.9 & 6.2 & 9.6 & 2.7 & 67,9 & 56,5 \\
\hline Cuiabá & 20.9 & 12.4 & 6.8 & 3.4 & 67,5 & 72,5 \\
\hline Manaus & 30.2 & 13.1 & 10.4 & 4.2 & 65,5 & 67,9 \\
\hline Campo Grande & 14.5 & 1.9 & 7.4 & 1.9 & - & 49 \\
\hline Recife & 15.5 & 7.1 & 11.2 & 3.2 & 27,7 & 54,9 \\
\hline Total & 354.2 & 166.1 & 156.7 & 58 & 55,7 & 65 \\
\hline
\end{tabular}

FONTE: $\mathrm{O}$ autor (2017).

A terceira tabela apresenta o total de recursos em milhões de reais de todos os candidatos que disputaram as eleições de 2012 e 2016 em cada uma das dez capitais, além do total de recursos com que cada um dos candidatos vencedores contou para a organização das suas respectivas campanhas eleitorais, nos dois pleitos. É importante ressaltar que foi considerado o número total de candidatos que concorreram às eleições e que, além de, em alguns casos, candidatos de determinados partidos, em especial do Partido Socialismo e Liberdade (PSoL), do Partido da Causa Operária (PCO) e do Partido Socialista dos Trabalhadores Unificados (PSTU), terem receitas consideravelmente baixas, algumas capitais tiveram mais candidatos do que outras, o que logicamente influencia nos números finais. $\mathrm{O}$ intuito desta pesquisa, entretanto, é avaliar as mudanças no total das receitas gerais e individuais. 
A campanha mais cara foi a da capital paulista, nas duas eleições analisadas - o que é esperado para a campanha da maior cidade do país —, considerando-se o total das receitas dos candidatos e a receita individual das candidaturas que venceram as eleições. Entretanto, percebe-se que não há relação direta entre receita e colégio eleitoral nesse sentido. Nas eleições de 2012, a segunda campanha de maior receita total foi a de Salvador, seguida pelas de Belo Horizonte, Fortaleza e Manaus - quarto, segundo, quinto e oitavo colégios eleitorais do país, respectivamente. Quanto às receitas individuais, o Rio de Janeiro teve a quarta campanha mais cara, antecedido por São Paulo, Salvador e Belo Horizonte.

Nas eleições de 2016, São Paulo continuou com a campanha eleitoral mais cara, mas passou a ser seguida por Rio de Janeiro, Belo Horizonte e Fortaleza no que diz respeito ao total de receitas, à soma de todos os candidatos e às receitas individuais dos candidatos vencedores. Em 2012 a campanha mais barata foi a de Campo Grande, no geral e individualmente - apesar de, no geral, Cuiabá ocupar tal posição. Pode-se observar também que, apesar do aumento - de sete para oito - nas capitais com segundo turno, houve uma diminuição considerável na receita total das campanhas e nas receitas dos candidatos vencedores.

Essa diminuição já era prevista, uma vez que a minirreforma estipulou um teto para as receitas dos candidatos, baseada nos colégios eleitorais das cidades. Em três cidades as eleições foram decididas em turno único em 2012 e em dois turnos em 2016: Rio de Janeiro, Recife e Belo Horizonte. Tais cidades também apresentaram o menor percentual de diminuição de custos das campanhas no geral - mas não quanto às receitas das candidaturas vencedoras.

O maior percentual de diminuição de receita de campanha considerando-se todos os candidatos foi o de Salvador, onde a receita de todos os candidatos foi 76,1\% menor em 2016, em comparação com o ano de 2012. Em relação às receitas individuais, os gastos com a campanha vitoriosa de Belo Horizonte diminuíram em 84,5\%, de 2012 para 2016. Em Campo Grande, os candidatos vencedores apresentaram as mesmas receitas nos dois anos, sendo este o único caso em que não houve diminuição em tal sentido. Entretanto, as campanhas individuais da cidade foram as mais baratas em ambos os anos. No geral, a diminuição dos valores das receitas totais das dez capitais foi de 55,7\%, enquanto a das receitas das campanhas vencedoras foi de $65 \%$.

Uma das mudanças mais significativas trazidas pela minirreforma foi a proibição de recursos de pessoas jurídicas nas campanhas, uma das variáveis que podem explicar a diminuição das receitas vista até agora. A quarta tabela apresenta dados sobre a origem dos 
ALVES, M; LIMA, B. Campanhas e legislação eleitoral: análise da "minirreforma" no contexto das eleições municipais brasileiras de 2016

recursos de financiamento de campanha em 2012. O objetivo específico de tal apresentação é avaliar qual foi a importância das doações de pessoas jurídicas para as campanhas e, posteriormente, pensar a sua proibição a partir desses números. Como se sabe, as cidades aqui analisadas são capitais importantes que, naturalmente, despertam a atenção dos principais partidos políticos e, também, dos principais financiadores de campanha - principalmente quando o candidato em questão é uma liderança política reconhecida ou quando tal candidatura se trata de uma reeleição, sendo as expectativas de vitória, neste caso, maiores.

TABELA 4 - VALORES EM MILHÕES DE REAIS RECEBIDOS DE PESSOAS JURÍDICAS EM 2012

\begin{tabular}{c|c|c}
\hline \multirow{2}{*}{ Cidade } & \multicolumn{2}{|c}{ Talor } \\
\cline { 2 - 3 } & 3.8 & Percentual \\
\hline São Paulo & 6.2 & 9,2 \\
\hline Belo Horizonte & 2.0 & 28,6 \\
\hline Rio de Janeiro & 1.8 & 11,3 \\
\hline Salvador & 4.8 & 25,9 \\
\hline Fortaleza & 2 & 32,7 \\
\hline Curitiba & 7.9 & 63,7 \\
\hline Cuiabá & 4.2 & 32,6 \\
\hline Manaus & 0.153 & 7,9 \\
\hline Campo Grande & 3.3 & 47,1
\end{tabular}

FONTE: O autor (2017).

Podem ser observados padrões entre as cidades analisadas. Primeiramente, em apenas três delas o valor destinado pelo setor privado não chega a atingir $10 \%$ do total arrecadado para a campanha: São Paulo, Salvador e Campo Grade. Há, ainda, um quarto caso, o da capital carioca, em que esse percentual atinge pouco mais de $11 \%$ do total arrecadado. Ainda, entre essas cidades, há casos opostos: os dos candidatos de São Paulo — do Partido dos Trabalhadores $(\mathrm{PT})$ - e Salvador — do Democratas (DEM) —, Fernando Haddad e ACM Neto, respectivamente. Enquanto o primeiro disputou um cargo eletivo pela primeira vez em 2012, o segundo é uma liderança política bastante conhecida não apenas no seu estado, eleito e reeleito para cargos executivos e legislativos.

Os perfis de financiamento dos dois candidatos se aproximam, ao passo que ambos não contaram com recursos privados expressivos e, também, devido ao fato de suas campanhas terem sido financiadas quase que na sua totalidade pelos seus próprios partidos, através do repasse dos diretórios estadual/distrital, dos diretórios nacionais e dos comitês específicos de campanha. Haddad foi uma grande aposta do PT na capital paulista, o que justifica tal investimento. Assim, como já foi dito, o perfil do financiamento do candidato à prefeitura do Rio de Janeiro se aproxima bastante ao de ACM Neto, uma liderança política 
estabelecida com uma estrutura partidária consolidada que financiou a sua campanha à reeleição.

Os percentuais apresentados na quarta tabela, apesar de esclarecedores quanto à dependência dos candidatos em relação aos recursos privados, certamente não são exatos, tratando-se apenas das doações diretas. Até as eleições de 2012, não havia a obrigatoriedade de se apresentar, nas contas de campanha, os nomes dos doadores originais — ou seja, parte considerável do dinheiro investido nas campanhas pelos comitês e diretórios tinha origem também na doação de pessoas jurídicas. $\mathrm{O}$ acesso aos doadores originais - que destinam dinheiro aos partidos, os quais, por sua vez, financiam as campanhas - é possível a partir das eleições gerais de 2014. Obviamente, com a proibição das doações de pessoas jurídicas, esse dado não existe nas prestações de contas de 2016.

As principais mudanças provocadas pela minirreforma envolvem o perfil dos financiamentos e o tempo das campanhas. Os dias de duração da campanha eleitoral foram reduzidos de 90 para 45. O período de campanha eleitoral no rádio e na TV também foi reduzido, de 45 para 35 dias. Além disso, no primeiro turno foram apresentados dois blocos de 10 minutos cada, para os candidatos ao executivo, e 80 minutos de spots por dia para os candidatos a prefeito e vereador (sendo $60 \%$ do tempo destinado àqueles e $40 \%$ a estes, com cada spot durando de 30 segundos a um minuto, vedando-se os spots de 15 segundos). Foi restringido também o uso de alguns recursos de propaganda "cinematográfica", tais como efeitos especiais, montagens, computação gráfica, desenhos animados e edições.

A respeito dos gastos de campanha para os cargos executivos, no caso das eleições de 2016, foi permitido que se gastasse até $70 \%$ do valor declarado pelo candidato com maior receita no pleito anterior, se as eleições tivessem sido decididas em um turno. No caso de segundo turno nas eleições de 2012, não se permitiria, em 2016, que esses gastos superassem 50\% do declarado na eleição anterior (isso porque as eleições decididas em dois turnos exigem, naturalmente, que dois dos candidatos tenham gastos elevados, devido às duas semanas adicionais de campanha). Ainda, os gastos com o segundo turno não poderiam ultrapassar $30 \%$ do teto fixado para o primeiro turno, o que representaria $70 \%$ ou $50 \%$ em relação à eleição anterior ${ }^{11}$.

Outra restrição importante diz respeito à contratação de cabos eleitorais: para cidades com até 30 mil eleitores, o número de cabos eleitorais não poderia ultrapassar $1 \%$ do eleitorado por candidato. Para cidades com mais de 30 mil eleitores, era permitida a contratação de um cabo eleitoral para cada mil eleitores. Todos os limites estipulados consideravam os gastos dos

\footnotetext{
${ }^{11}$ Para as cidades pequenas, ainda, foram definidos dois tetos, sendo que, nas cidades com até 10 mil eleitores, foi estabelecido um teto de 100 mil reais.
} 
ALVES, M; LIMA, B. Campanhas e legislação eleitoral: análise da "minirreforma" no contexto das eleições municipais brasileiras de 2016

candidatos e dos seus respectivos comitês financeiros, desde que houvesse um repasse de tais valores aos candidatos. De acordo com o art. 19 da Lei $\mathrm{n}^{\circ}$ 9.504/1997, os partidos devem constituir comitês financeiros para arrecadar e destinar recursos às campanhas eleitorais. Os partidos podem escolher pela composição de um comitê financeiro único, que concentra todas as atividades de gestão de recursos (tais como a abertura de contas bancárias e a administração de recibos) ou pela criação de um comitê financeiro para cada disputa eleitoral.

Os limites de gastos ${ }^{12}$ foram divulgados pelo TSE por meio da Portaria $\mathrm{n}^{\mathrm{o}} 704$, de $1^{\mathrm{o}}$ de julho de 2016 — data anterior à de início da campanha eleitoral daquele ano, mas quando os partidos já podiam indicar os seus candidatos e articular seus apoios. Segundo a portaria, o teto de limite de gastos para prefeito, em todo o país, variaria de 108 mil reais, no caso das cidades pequenas (que somam 3794 municípios, ou $68 \%$ do total de municípios do país), a 45,4 milhões de reais ${ }^{13}$, como foi o caso do primeiro turno das eleições para a prefeitura de São Paulo, a maior cidade brasileira. No caso de segundo turno, na mesma cidade, o teto é de 13,6 milhões — ou seja, um candidato que dispute os dois turnos da eleição na capital paulista pode ter uma despesa de até 59 milhões de reais, o maior valor do país. A tabela abaixo apresenta as dez cidades com os maiores tetos de gastos referentes à disputa de primeiro turno das eleições municipais para prefeito de 2016.

TABELA 5 - AS DEZ CIDADES COM OS MAIORES TETOS DE GASTOS NA DISPUTA PARA PREFEITO DE 2016

\begin{tabular}{c|c|c}
\hline Cidades & Primeiro turno & Segundo turno \\
\hline São Paulo & 45,4 & 13,6 \\
\hline Belo Horizonte & 26,6 & 8 \\
\hline Rio de Janeiro & 19,8 & 5.9 \\
\hline Salvador & 14,6 & 4.4 \\
\hline Fortaleza & 12,4 & 3.7 \\
\hline Curitiba & 9,5 & 2.8 \\
\hline Cuiabá & 9 & 2.7 \\
\hline Manaus & 8,9 & 2.6 \\
\hline Campo Grande & 6,6 & 2 \\
\hline Recife & 6,6 & 1.9 \\
\hline
\end{tabular}

FONTE: $O$ autor (2017).

O teto de gastos estipulado em milhões de reais pela minirreforma é baseado no colégio eleitoral e no maior valor gasto declarado na campanha anterior para o mesmo cargo no mesmo município. Supondo que todos os candidatos atinjam esse teto, as médias também serão correspondentes aos respectivos colégios. Como pode ser observado, apesar de a relação

\footnotetext{
${ }^{12}$ Os valores foram atualizados pelo TSE de acordo com a variação do INPC do IBGE. Para os municípios de até 10 mil eleitores, com limite de gasto de 100 mil reais para prefeito, o índice foi de 8\%, referente ao INPC acumulado de outubro de 2015 a junho de 2016. Isso porque os valores foram estipulados a partir da Lei $\mathrm{n}^{\mathrm{o}} 13.165$, que é de 2015.

${ }^{13}$ Para o cargo de vereador o valor vai de 10,8 mil reais a 26,8 milhões de reais.
} 
entre colégio eleitoral e recursos variar entre os casos apresentados, o número de votantes em uma cidade é uma variável importante no encarecimento das campanhas dos candidatos, assim como o fato de a decisão se dar em turno único ou turno e returno, previsto na nova legislação. São Paulo, por exemplo, apresenta o maior colégio eleitoral e, por consequência, o maior teto de gastos para o pleito de 2016.

TABELA 6 - DESPESAS EM MILHÕES DE REAIS POR CIDADE, TOTAL DE DESPESAS DO CANDIDATO VENCEDOR NAS ELEIÇÕES MUNICIPAIS DE 2012 E 2016 NAS DEZ CAPITAIS E O PERCENTUAL DE DIMINUIÇÃO DE RECEITA

\begin{tabular}{c|c|c|c|c|c|c}
\hline \multirow{2}{*}{ Cidade } & \multicolumn{2}{|c|}{ Despesas em 2012 } & \multicolumn{2}{c|}{ Despesas em 2016 } & \multicolumn{2}{c}{ Percentual de diminuição } \\
\cline { 2 - 7 } & Total & Candidato & Total & Candidato & Total & Candidato \\
\hline São Paulo & 133.1 & 67.9 & 43.9 & 12.3 & 67,0 & 81,8 \\
\hline Belo Horizonte & 50.2 & 28.5 & 31.9 & 4.1 & 36,4 & 85,6 \\
\hline Rio de Janeiro & 30.3 & 21.2 & 25.6 & 9.4 & 15,5 & 55,6 \\
\hline Salvador & 46.3 & 21.9 & 12.8 & 9.9 & 72,3 & 54,7 \\
\hline Fortaleza & 35.6 & 18.5 & 19.9 & 10.3 & 44,1 & 44 \\
\hline Curitiba & 30.8 & 6.8 & 11.9 & 3.5 & 61,4 & 48,5 \\
\hline Cuiabá & 28.3 & 13.5 & 12.0 & 5.4 & 57,6 & 60,7 \\
\hline Manaus & 30.7 & 13.2 & 14.5 & 7.2 & 52,8 & 45,4 \\
\hline Campo Grande & 21.2 & 1.9 & 6.9 & 1.9 & 32,5 & - \\
\hline Recife & 15.6 & 7.1 & 15.7 & 6.0 & 0,6 & 15,4 \\
\hline Total & 422.1 & 200.5 & 195.2 & 70.4 & 53,7 & 64,8 \\
\hline
\end{tabular}

FONTE: $\mathrm{O}$ autor (2017).

A Tabela 6 apresenta a somatória dos gastos, em milhões de reais, de todos os candidatos das dez cidades selecionadas e dos candidatos vencedores nos pleitos de 2012 e 2016. A partir dos dados, pode-se observar que, em pelo menos metade das cidades, houve um percentual de diminuição de $50 \%$ nos gastos das campanhas, sendo que em três casos tais gastos diminuíram em mais de 33\%, considerando-se a somatória de todos os candidatos em cada uma dessas capitais. Novamente, deve enfatizar-se a variação no número de concorrentes em cada caso e em cada eleição, além de o fato de alguns partidos apresentarem menor receita e, por consequência, gastos significativamente menores. O menor percentual de diminuição se vê no Rio de Janeiro, cidade que em 2012 decidiu as eleições em turno único e, em 2016, com turno e returno.

Os dados referentes à diminuição percentual nos gastos dos candidatos vencedores seguiram a mesma linha dos dados relativos aos gastos totais: na maioria dos casos, houve uma diminuição significativa. Destacamos, nesse sentido, as cidades de São Paulo e Belo Horizonte, nas quais as campanhas dos candidatos vencedores foram, em 2016, 80\% mais baratas do que as do ano de 2012. O caso da cidade de São Paulo é emblemático, pois, apesar

\footnotetext{
${ }^{14}$ No caso de Recife, não houve uma diminuição de despesas, mas sim um aumento de $0,6 \%$ nos gastos em relação ao pleito anterior.
} 
ALVES, M; LIMA, B. Campanhas e legislação eleitoral: análise da "minirreforma" no contexto das eleições municipais brasileiras de 2016

de a eleição de 2016 ter sido decidida em turno único, diferentemente da anterior, o percentual de diminuição dos gastos de campanha naquele ano foi muito elevado. Ainda assim, São Paulo tem a campanha para prefeito mais cara do país. Dois casos a serem destacados, também, são os de Recife, que apresentou a menor diminuição nos gastos com o candidato vencedor $(15,4 \%)$, e Campo Grande, em que os gastos se mantiveram os mesmos em ambas as eleições.

Os dados das duas últimas tabelas atestam como a regulamentação financeira das campanhas promovida pela minirreforma diminuiu substancialmente os gastos de campanha. Considerando-se a soma dos tetos de gastos de 2016, os candidatos vencedores gastaram menos do que o teto estipulado. São Paulo e Salvador foram as únicas que tiveram eleições decididas em turno único em 2016. Na capital paulista, por exemplo, o candidato vencedor em 2012, Fernando Haddad (PT), dispôs, nos dois turnos concorridos, de uma quantia total de 42 milhões de reais, enquanto em 2016, sendo o teto de gastos estipulado de 43 milhões, o candidato vencedor, João Dória (PMDB), apresentou um total de despesas de 12,3 milhões de reais. Considerando-se que a decisão se deu em turno único, podemos aferir que a cidade que comprovadamente tem a campanha mais cara entre as dez capitais analisadas apresentou uma campanha substancialmente mais barata do que a do ano anterior.

Por fim, será avaliado se as restrições específicas impostas pela minirreforma em relação ao tempo de propaganda eleitoral no rádio e na TV, assim como a limitação na contratação de pessoal, são coerentes com o objetivo de tornar as campanhas mais baratas. A questão que se coloca é a seguinte: quais são as atividades de campanha ${ }^{15}$ que concentram a maior parte dos recursos? A próxima tabela apresenta os percentuais de gastos em atividades de campanha, reunidos em quatro grupos ${ }^{16}$, para cada uma das capitais analisadas.

\footnotetext{
${ }^{15}$ Segundo estabelecido pelo TSE para o sistema de prestação de contas eleitorais.

${ }^{16}$ Comunicação: publicidade feita por jornais e revistas; produção de programas de rádio, televisão ou vídeo; produção de jingles, vinhetas e slogans; criação de páginas na internet; publicidade feita por meio de placas, estandartes e faixas; publicidade feita por meio de materiais impressos; publicidade feita com carros de som; correspondências e despesas postais; comícios; pesquisas ou testes eleitorais. Estrutura/transporte: materiais de expediente; energia elétrica; água; locação/cessão de bens imóveis; telefone; bens permanentes; despesas com transporte ou deslocamento; cessão ou locação de veículos; locação/cessão de bens móveis; combustíveis e lubrificantes. Pessoal: despesas com pessoal; serviços prestados por terceiros; baixa de recursos estimáveis em dinheiro; alimentação. Outros: diversas (a especificar); encargos financeiros, taxas bancárias e/ou operações de cartão de crédito; impostos, contribuições e taxas; encargos sociais; multas eleitorais.
} 
TABELA 7 - PERCENTUAL GASTO EM ATIVIDADES DE CAMPANHA POR GRUPO EM 2012

\begin{tabular}{c|c|c|c|c}
\hline \multirow{2}{*}{ Cidade } & \multicolumn{4}{|c}{ Grupos de atividades } \\
\cline { 2 - 5 } & Comunicação & Estrutura/transporte & Pessoal & Outros \\
\hline São Paulo & 81,9 & 1,5 & 16,5 & 0,1 \\
\hline Belo Horizonte & 21,6 & 4 & 68,7 & 3,5 \\
\hline Rio de Janeiro & 9 & 5,7 & 84,3 & 0,6 \\
\hline Salvador & 33,5 & 5,1 & 58,6 & 0,5 \\
\hline Fortaleza & 48,2 & 8,9 & 33 & 0,9 \\
\hline Curitiba & 36,2 & 7,3 & 52,6 & 0,2 \\
\hline Cuiabá & 14,8 & 10,6 & 58,5 & 0,1 \\
\hline Manaus & 32,1 & 2,3 & 56 & 0,2 \\
\hline Campo Grande & 32 & 3,8 & 40,4 & 0,3 \\
\hline Recife & 75,6 & 4,6 & 14,1 & 0,8 \\
\hline
\end{tabular}

FONTE: $O$ autor (2017).

Segundo os dados da Tabela 7, as atividades de "comunicação" concentram a maior parte dos gastos de campanha em São Paulo, Fortaleza e Recife — as mesmas cidades em que os gastos com pessoal ocupam o segundo lugar no percentual de gastos. Em Belo Horizonte, Salvador, Curitiba, Cuiabá, Manaus e Campo Grande, a maior concentração de recursos está nas atividades relacionadas à categoria "pessoal", seguida de "comunicação". O único caso que foge aos padrões apresentados é o do Rio de Janeiro, em que a categoria "comunicação", apesar de estar em segundo lugar, não apresenta um número significativo no percentual de gastos.

Sobre as atividades da categoria "comunicação", a "produção de programas de rádio, televisão ou vídeo", a "publicidade por placas, estandartes e faixas" e a "publicidade por material impresso" são as que concentram maiores percentuais de gastos de campanha, exceto no Rio de Janeiro. Os gastos com material de campanha podem ter diminuído devido à redução dos dias de campanha eleitoral, principalmente no que diz respeito aos custos com a produção da propaganda eleitoral na TV, que exige uma maior estrutura e envolve, necessariamente, contratação especializada.

$\mathrm{Na}$ categoria "pessoal", duas atividades podem ser destacadas: "despesas com pessoal" e "serviços prestados por terceiros". A primeira, denominada pelo TSE como "contratação de pessoal para realizar atividades de militância e mobilização", faz referência principalmente à contratação de pessoal não necessariamente especializado para a realização de atividades de rua, como o porte de bandeiras e a distribuição de panfletos (nas casas e durante eventos de campanha) — ou seja, atividades relacionadas à publicidade feita por meio de material impresso, que também concentra recursos financeiros. 
ALVES, M; LIMA, B. Campanhas e legislação eleitoral: análise da "minirreforma" no contexto das eleições municipais brasileiras de 2016

Ainda, a categoria "pessoal" também concentra recursos relativos à atividade de “serviços prestados por terceiros", já que esta envolve, por exemplo, a contratação de pessoas para a realização de serviços técnicos, consultorias e assistências a partidos e candidatos, além da produção de material de campanha - que também pode ser enquadrada nessa categoria. Estas atividades estão interligadas, sendo essenciais para partidos e candidatos na organização e no desenvolvimento das suas campanhas eleitorais e reportando à finalidade última dessas campanhas - a comunicação.

Sendo assim, é coerente afirmar que as alterações pontuais previstas pela minirreforma a respeito da diminuição dos dias de campanha na TV e do limite de contratação de pessoal foram acertadas, uma vez que foi imposto um limite de gastos paralelo à diminuição das duas atividades que mais concentram gastos. A tabela seguinte apresenta dados sobre os gastos com produção de programas de rádio, televisão e vídeo, conforme as categorias especificadas pelo TSE para a prestação de contas eleitorais de 2012 e 2016 . O objetivo de se apresentarem de tais dados é saber se a diminuição das receitas e dos limites de gatos impostos, paralela à diminuição nos dias de HGPE, alterou o padrão de investimento na produção de material para TV.

TABELA 8 - TOTAL EM MILHÕES DE REAIS E PERCENTUAL GASTO COM A PRODUÇ̃̃O DE PROGRAMAS DE RÁDIO, TELEVISÃO E VÍDEO EM 2012 E 2016

\begin{tabular}{c|c|c|c|c}
\hline \multirow{2}{*}{ Cidade } & \multicolumn{3}{|c}{ Produção de programas de rádio, televisão e vídeo } \\
\cline { 2 - 5 } & \multicolumn{2}{|c}{2012} & \multicolumn{2}{c}{2016} \\
\cline { 2 - 5 } & Total & Percentual & Total & Percentual \\
\hline São Paulo & 29.0 & 44 & 5.1 & 42 \\
\hline Belo Horizonte & 1.5 & 5,7 & 1.8 & 18,7 \\
\hline Rio de Janeiro & - & - & 1.7 & 18,1 \\
\hline Salvador & 2 & 9,1 & 2.1 & 31,7 \\
\hline Fortaleza & 2.5 & 13,5 & 3.6 & 13,9 \\
\hline Curitiba & 0.600 & 9,7 & 0.489 & 48,5 \\
\hline Cuiabá & 0.522 & 3,8 & 2.6 & 32,1 \\
\hline Manaus & 1 & 8,2 & 1.1 & 34,9 \\
\hline Campo Grande & 0.325 & 16,8 & 0.630 & \\
\hline Recife & 2.9 & 41,8 & 2.1 & \\
\hline FONTE: O autor $(2017)$ & & & &
\end{tabular}

FONTE: $\mathrm{O}$ autor (2017).

Os dados da Tabela 8 referem-se ao total, em milhões de reais, investido na categoria denominada "produção de programas de rádio, televisão ou vídeo", nas campanhas de 2012 e 2016, pelas candidaturas vencedoras em cada uma das capitais. Como pode ser observado, houve diminuição no total investido entre os dois anos em apenas três das dez capitais analisadas. Deve-se destacar a cidade de São Paulo, que passou de 29 milhões para 5 milhões 
de reais — uma diminuição considerável, apesar da redução de dias de HGPE estabelecida pela minirreforma e do fato de a decisão ter ocorrido em primeiro turno em 2016.

Das sete cidades que apresentaram aumento de recursos investidos - Belo Horizonte, Rio de Janeiro, Salvador, Fortaleza, Cuiabá, Manaus e Campo Grande —, apenas a capital carioca - que não declarou recursos na eleição anterior —, Fortaleza e Cuiabá apresentam valores significativos a esse respeito - com aumentos de um milhão e 700 mil reais, um milhão e 100 mil reais e dois milhões de reais, respectivamente. A variação no investimento entre as demais cidades está entre 100 mil e 300 mil reais.

Nas eleições de 2016, as candidaturas vencedoras das dez capitais analisadas concentraram um percentual considerável de recursos na produção de material para TV. O aumento do percentual, em relação a todos os gastos de campanha, cresceu em oito dos dez casos. Entretanto, nas cidades onde esse percentual diminuiu (São Paulo e Recife), esse número ainda é bastante alto: $42 \%$ e $34,9 \%$.

Portanto, apesar da diminuição dos dias de propaganda eleitoral, do tempo de HGPE e do número de inserções na TV, os gastos com tal categoria aumentaram na maior parte dos casos. Além disso, as candidaturas passaram a concentrar mais recursos na produção de material para esse meio em relação às demais atividades e ao pleito anterior. O aumento dos recursos destinados à TV pode ter ocorrido em virtude das limitações impostas pela nova legislação, além de indicar o crescimento da importância estratégica da televisão nas campanhas eleitorais, principal canal de comunicação em um contexto de incerteza comum em períodos de reforma institucional.

\section{CONSIDERAÇÕES FINAIS}

As eleições municipais de 2016 certamente representaram um marco para os estudos eleitorais no Brasil, principalmente pelas alterações na legislação eleitoral, que promoveram mudanças em pontos fundamentais para a organização das campanhas. Assim, o objetivo deste artigo foi analisar a dinâmica financeira das eleições após a minirreforma de 2015, a partir do caso das eleições municipais em dez capitais brasileiras, em 2012 e 2016, privilegiando-se a identificação das questões específicas que a reforma visou sanar. Para tanto, foram utilizadas as prestações de contas oficiais das campanhas vencedoras de 2012 e 2016 das dez capitais selecionadas.

As receitas e as despesas de campanha diminuíram de forma significativa quando comparados os dados de 2012 e 2016, tanto no total quanto considerando-se as campanhas 
ALVES, M; LIMA, B. Campanhas e legislação eleitoral: análise da "minirreforma" no contexto das eleições municipais brasileiras de 2016

dos candidatos vencedores em cada uma das cidades - o que era previsto, dado o teto imposto pela nova legislação e, também, considerando-se a proibição da doação de recursos financeiros por parte de pessoas jurídicas para partidos e candidatos para fins de financiamento de atividades de campanha. Ainda, como foi ressaltado, em todas as cidades analisadas os gastos com as campanhas ficaram muito abaixo desse teto. Outro importante fator a ser considerado é a inflação referente ao período: segundo dados do Índice Nacional de Preços ao Consumidor (IPCA), entre 2012 e 2016 a inflação acumulada foi de 35,1\%, o que fortalece o argumento referente à possível causa da redução do custo das campanhas.

Assim, a proibição da arrecadação de recursos de pessoas jurídicas foi essencial para essa diminuição. Como argumentado anteriormente, os dados relativos à campanha de 2012 não são significativos em todos os casos analisados, mas não podem ser ignorados (o que poderia ser sugerido, devido à falta de informação sobre os doadores originais). Esse argumento ganha força com os dados de 2016, que apontam para uma arrecadação significativamente menor - o que indica que grande parte das doações de pessoas jurídicas para as campanhas municipais em 2012 foram realizadas através das legendas, sendo tais doações repassadas para os candidatos.

Ainda, o tempo de campanha foi um aspecto essencial na minirreforma. A lógica é simples: menos dias de campanha, menores os gastos. Entretanto, apesar da diminuição dos dias e do tempo de propaganda eleitoral na TV, houve uma maior concentração de recursos na produção desse material. Tal dado corrobora a literatura que indica a centralidade desse meio de comunicação, essencial para a organização das campanhas - considerando-se, inclusive, que as eleições de 2016 ocorreram em um contexto de mudanças substanciais na legislação, o que gera um ambiente de incerteza.

Dessa forma, a diminuição no tempo de campanha não pareceu uma medida eficaz para o barateamento das campanhas, uma vez que a concentração e o volume de recursos investidos nessa área foi maior em quase todos os casos. Além disso, uma campanha menor significa menos exposição à informação política para o eleitor, além de menos tempo para informar e convencer o eleitorado para os partidos e candidatos. Por fim, a mudança no perfil do financiamento das campanhas estabelecido pela minirreforma foi eficiente no sentido de tornar os partidos menos dependentes de um setor específico, mas não impediu a concentração de recursos nos grandes partidos. 


\section{REFERÊNCIAS}

ALBUQUERQUE, A.. Advertising ou propaganda? O audiovisual político brasileiro numa perspectiva comparada. Alceu(PUCRJ), Rio de Janeiro, v. 5, n.10, p. 215-227, 2005.

AZEVEDO, F. Mídia e democracia no Brasil: relações e entre o sistema de mídia e o sistema político. Opinião Pública, Campinas, v. 12, n. 1, p. 88-113, abr./maio 2006.

BORBA, F. A propaganda negativa: estratégia e voto nas eleições brasileiras. Tese (Doutorado em Ciência Política) - Instituto de Estudos Sociais e Políticos (IESP), Universidade do Estado do Rio de Janeiro, Rio de Janeiro, 2012.

BRASIL. Casa Civil. Lei $n^{\circ}$ 9.504, de 30 de setembro de 1997. Estabelece normas para as eleições. 1997. Disponível em: <http://www.planalto.gov.br/ccivil_03/leis/L9504.htm>. Acesso em 10/09/2017.

CERVI, E. Financiamento de campanhas e desempenho eleitoral no Brasil: análise das contribuições de pessoas físicas, jurídicas e partidos políticos às eleições de 2008 nas capitais de Estado. Revista Brasileira de Ciência Política, v. 4, p. 135-167, 2010.

O "tempo da política" e a distribuição dos recursos partidários: uma análise do HGPE. Em Debate, Belo Horizonte, v. 2, n. 8, p. 12-17, ago. 2010.

. Doações de campanha e desempenho eleitoral: uma análise comparativa sobre as eleições para prefeitos de capitais brasileiras em 2008 e 2012. Agenda Política, v. 1, n. 1, p. 26-54, 2013.

FARRELL, D. Political Parties in a Changing Campaign Environment. In: KATZ, R. S.; CROTTY, W. Handbook of Party Politics. SAGE Publications, 2006.

LISI, M. O comportamento eleitoral nas democracias contemporâneas: um desalinhamento permanente? Portugal em perspectiva comparada. In: FREIRE, A. Eleições e sistemas eleitorais no século XX português: uma perspectiva histórica. Lisboa: Edições Colibri, 2011.

MANCUSO, W. P.; FERRAZ, A. S. As distorções do financiamento de campanhas. Revista Fórum, v. 108, 2012.

MANCUSO, W. P.; SPECK, B. W. Financiamento empresarial e desempenho eleitoral no Brasil: um estudo das eleições para deputado federal em 2010. Trabalho apresentado no 8. Workshop Empresa, Empresários e Sociedade, Curitiba, 2012.

MANIN, B. As metamorfoses do Governo Representativo. Revista Brasileira de Ciências Sociais, n. 29, p. 5-34, out. 1995.

A democracia do público reconsiderada. Novos Estudos Cebrap, São Paulo, n. 97, p. 115-127, 2013. 
ALVES, M; LIMA, B. Campanhas e legislação eleitoral: análise da "minirreforma" no contexto das eleições municipais brasileiras de 2016

MARCELINO, D. Sobre dinheiro e eleições: um estudo dos gastos de campanha para o Congresso Nacional em 2002 e 2006. Dissertação (Mestrado em Ciências Sociais) Universidade de Brasília, Brasília, 2010.

MARENCO, A. Financiamento de campanhas eleitorais. In: AVRITZER, L. et al. (Ed.). Corrupção: ensaios e críticas. Belo Horizonte: Editora UFMG, 2008.

MAZZOLENI, G. La comunicación política. Madrid: Alianza Editorial, 2010.

NORRIS, P. A Virtuous Circle: Political Communications in Postindustrial Societies. Cambridge: Cambridge University Press, 2000.

PEIXOTO, V. M. Eleições e financiamento de campanhas no Brasil. Tese (Doutorado em Ciência Política) - Instituto Universitário de Pesquisas do Estado do Rio de Janeiro, Rio de Janeiro, 2010.

RIBEIRO, R. J. Financiamento de campanha (público versus privado). In: AVRITZER, L.; ANASTASIA, F. (Org.). Reforma política no Brasil. Belo Horizonte: Editora UFMG, 2006.

SAMUELS, D. Money, Elections and Democracy in Brazil. Latin American Politics and Society, v. 43, n. 2, p. 27-48, 2001.

Pork Barreling is not Credit Claiming or Advertising: Campaign Finance and the Source of the Personal Vote in Brazil. The Journal of Politics, v. 64, n. 3, p. 845-863, 2002.

. SAMUELS, D. Financiamento de campanhas e propostas de reforma. In: SOARES, G. A. D.; RENNÓ, L. R. Reforma política: lições da história recente. 1. ed. Rio de Janeiro: FGV Editora, 2006. p. 133-156.

SPECK, B. W. O financiamento político e a corrupção no Brasil. In: BIASON, R. C.; (Ed.). Temas de corrupção política. São Paulo: Balão Editorial, 2012.

TRIBUNAL REGIONAL FEDERAL DA $5^{\mathrm{a}}$ REGIÃO. Eleitores do Recife devem fazer $o$ recadastramento biométrico. 2013. Disponível em: <http://trf5.jusbrasil.com.br/noticias/100320359/eleitores-do-recife-devem-fazer-o-recadastramentobiometrico>. Acesso em 10/09/2017. 